\title{
Solutions For Applying The Educational Technology In Vietnamese Vocational Education Institutions
}

\author{
Bui Van Hong \\ Ho Chi Minh University of Technology and Education
}

\begin{abstract}
In the context of growing science and technology, increasing knowledge, more diverse learning needs of learners and especially the trend of international integration in vocational education as at present, the ability to apply technology and innovate teaching methods in training plays a decisive role to the quality of human resource training. Based on the analysis of the impact of the Fourth Industrial Revolution (Industry 4.0) on the vocational education system and the trend of innovation in human resource training in vocational education institutions in Vietnam, the article proposes solutions for applying educational technology in training at the vocational education institutions, meeting the needs of innovation and improving the quality of Vocational Education today.
\end{abstract}

Keywords: Vocational education; Educational technology; Industrial Revolution 4.0; Solutions for applying educational technology

\section{INTRODUCTION}

Training quality human resources to meet business needs and international integration is one of the important goals of the vocational education today. In order to realize this goal, in addition to the renovation of training program and improving the professional capacity for teachers, the ability to apply advanced educational technology and innovate teaching methods is considered an important and key factor in the current digital age.

In the context of growing science and technology, increasing knowledge, more diverse learning needs of learners, the strong impact of Industrial 4.0 and STEM (Science, Technology, Engineering, Mathematic), many new professions have appeared in society, affecting the industry structure and the requirement of human resource training for vocational education. At the same time, the continuous increase in the amount of knowledge required for a field of study has posed a huge challenge for traditional courses in the form of face-to-face learning in term of the ability to meet the diverse learning needs of learners and to innovate teaching methods. Therefore, the application of education technology and mobile devices to build digital and online classes, to meet the diverse learning needs of every learner in terms of learning time, location, content, form and process in the period of knowledge explosion has received much attention in teaching practice and in research. Therefore, in the current context, to perform the task of innovation and improving the quality of human resource training in the field of vocational education, the study of solutions for applying advanced educational technology in training has an urgent and practical significance.

With the aim of proposing solutions for applying educational technology in training at vocational education institutions, the article focuses on analyzing the impact of Industry 4.0 to vocational education, sharing experience in training high-quality human resources at HCM University of Technology and Education, thereby proposing solutions suitable to the needs of innovation and improving the quality of vocational education today. 


\section{Research methodology}

\section{RESEARCH CONTENT}

The paper uses theoretical research methods, practical observation methods and in-depth interview methods to collect scientific information, content and propose solutions appropriate to the objectives of the article, including:

- Collect and analyze content from documents related to training activities in vocational education, the impact of Industry 4.0 to the vocational education system and the impacts on future career changes.

- Summarize experience in training high-quality human resources at HCM University of Technology and Education.

- Discuss with the Boards of Administration, Heads of Training Department and Deans of some vocational education institutions in Ho Chi Minh City (HCMC) on the current situation and needs of vocational educators.

- Discuss with officials of the vocational education institutions and education experts on general assessments on the ability of vocational educators to apply technology and teaching method innovations.

- Analyze the impacts of the context on the vocational education system as a basis for proposing solutions to develop suitable vocational educators.

\section{Impact of Industry 4.0 on vocational education}

The Industry 4.0 based on the integration of a series of new technologies, such as artificial intelligence, IoT, Big data, cloud computing, etc., is developing rapidly and strongly, impacting on all aspects of socio-economic life, including vocational education[1]. With breakthrough technological developments, this revolution will quickly transform the structure of industries in the future. At that time, many traditional industries will disappear with the birth of other new professions. This affects the change of structure and list of training professions in the whole system of vocational education. In particular, with the development of artificial intelligence and intelligent robots, automated machines, people will gradually be replaced in many career fields. [1]. Therefore, to ensure their career, employees must actively equip their knowledge and professional skills in accordance with the requirements of the job in the new situation. Thus, training program and methods of vocational education institutions must also transform in the direction of openness and flexibility accordingly to meet the diverse learning needs of learners.

The impact of the Industry 4.0 on vocational education today includes the application of IoT technology in the development of Dital Pedagogy and virtual reality technology in teaching. In teaching activities, the role of teachers will gradually shift from transmitting knowledge to guiding students to discover new knowledge. At the same time, digital and virtual classes will thrive. Learners will get used to learning through the internet, with the guidance of virtual teachers. This is an indispensable development trend in human resource training in the vocational education sector.

\section{Impacts on future career changes}

According to Lee Rainie (2017), a research center on American life and internet projects, the truth about future careers will change under the impact of digital technology and artificial intelligence as follows [2]:

(1) The nature of work is changing with the rise of the knowledge economy.

(2) Since 1990, jobs have grown fastest in the field of health and education services.

(3) Automation, robots, artificial intelligence are replacing the traditional jobs of workers.

(4) People think of many occupations that are at risk of not being carried out by humans (possibly replaced by robots or computers). 
(5) People feel more anxious than optimistic about the future's automation.

(6) Workers feel more positive than negative perspectives on the overall impact of technology on careers.

(7) Highly-skilled workers prefer to talk more about technology, which increases opportunities, creating more attractive professions.

(8) People think that computer knowledge, social behavior, communication skills and training opportunities are the keys to success.

(9) Americans think that schools (both public and private schools) are most responsible for creating certainty for workers with appropriate skills.

(10) Changing education and vocational education programs is inevitable.

\section{Comments:}

Under the impact of Industry 4.0 and the strong development of digital technology as at present, the training of high quality human resources in the field of vocational education needs innovations to adapt as follows:

- The trend of borderless and shared education

- Personalization of the training programs; open training program with the outline must account for over $50 \%$ to help teachers easily transform careers

- Application of numerical teaching methods according to combined teaching model and reverse classroom: Blended Learning, Flip - Flopped Classroom, Project based Learning, Learning by doing; Work based learning, etc.

- Innovation, interdisciplinary and transdisciplinary

- The role of the teachers changes from transmitting knowledge to guiding students to study and research to discover new knowledge

- Equipping students with knowledge, technical skills, and technical innovation with the development of autonomy and self-responsibility capacity; professional ethics education, labor discipline and industrial behaviour.

\section{Innovative trend in human resource training at vocational training institutions in Vietnam}

In the context of vocational education subject to the strong impact of Industry 4.0, in order to meet the task of innovation and improving the quality of human resource training, vocational education institutions in Vietnam are actively innovating training activities such as improving professional qualifications, skills, practice skills, foreign language skills and soft skills of teachers; innovating methods and applying technology in teaching. This shows that vocational training institutions are focusing on strong innovation to adapt to the development of society, specifically as follows:

(1) Redesign training program according to capacity approach

(2) Provide admission advice, career guidance and educational communication

(3) Apply IT in all fields of operation

(4) Innovating teaching method according to application of digital teaching, blended learning with LMS, Project based Learning.

(5) Improve English proficiency, international relations and international projects

(6) Join comprehensive cooperation with businesses

(7) Develop teachers to adapt to the impact of Industry 4.0

(8) Develop creative and scientific playground for students

(9) Maintain quality assurance and international accreditation of educational institutions

(10) Develop information technology infrastructure and Big data 
In particular, the deployment of technology application in training and innovation of teaching methods is considered a breakthrough solution in the task of improving the quality of vocational education today.

\section{Technology application solutions for training at vocational training institutions in Vietnam}

\section{Strengthening the capacity of digital technology applications}

This solution helps schools have the ability to organize, operate and manage the online learning system.

Schools actively assess the situation of facilities, internet infrastructure and technological equipment, thereby supplementing equipment in accordance with the general technical requirements and the needs of teaching at each schools, including:

- Determine the scale of digital teaching organization

- Upgrade or equip internet network infrastructure

- Build digital classrooms and equip appropriate technological equipment such as TVs, computers, cameras and some other smart devices.

\section{Building an online learning system and sharing digital teaching resources among schools}

The foundation of digital teaching is the LMS (Learning Management System). Therefore, this solution helps schools build the LMS for online learning in accordance with the requirements of course deployment.

The online learning system is built on the following basic requirements:

- Unlimited by space and time: allowing flexibility for learners to have time and place to study.

- Attracting users: multimedia applications helping teaching content integrate text, images, audio and colors to increase the attractiveness for lessons.

- Flexible learning process: allowing learners to adjust their learning process by themselves, choosing the most appropriate way of learning with their circumstances.

- Easy and random access: allowing learners to find their own study skills under the help of online materials.

- Regular updates: course content updated regularly to best meet the learning needs of learners.

- Collaborative learning: Learners can easily exchange online with each other during the learning process. Exchange can take place between teachers and learners and between learners.

In addition, in order to improve online teaching capacity and promote the development of sustainable digital teaching, the schools cooperate in developing online teaching as follows:

- Establish an online learning system, or link to exploit the existing system of an educational institution.

- Develop collaborative regulations between schools that exploit the online learning system and common digital resources.

- Develop a common digital learning resource suitable to the characteristics of vocational education, such as learning materials and ebooks; electronic lectures; teaching videos; etc. 


\section{Promoting innovation of teaching methods in the vocational education system}

This solution helps to promote learners' positive in the process of organizing teaching, gradually changing the role of teachers from imparting knowledge to guiding students to discover new knowledge, specifically as follows:

- Promulgate policies to promote and support vocational educators to actively innovate teaching methods and change the role from transferring knowledge to guide students to discover new knowledge themselves.

- Develop a plan to foster active teaching methods for vocational educators.

- Set up technology and education universities, especially HCM University of Technology and Education organizes fostering teachers on skills to apply positive teaching methods such as Project-based Learning, Learning by doing, Work-based Learning, etc.

- Build open learning space, technology innovation space at vocational education institutions to serve the active use of teaching method in teaching.

- Develop curriculum, learning materials and organize training of teachers on the capacity to apply digital teaching methods such as LMS structure; Building lectures and digital learning materials; Organization and management of learning outcomes in LMS.

In addition, vocational training institutions should have policies to support and encourage teachers and learners to participate in online learning as follows:

- Instruct teachers and learners to use the online learning system, build electronic lessons and digitize teaching content..

- Provide a policy of credit accumulation for learners through online learning.

- Combine online and traditional classroom assessment on learners' results.

\section{CONCLUSIONS}

Training quality human resources to meet business needs and international integration is one of the important goals of the vocational education today. Under the direct and strong impact of smart devices and IoT technology, there has been a rapid change in learners' needs and career structure in vocational training. Therefore, the ability to apply technology and innovate teaching methods is an important factor that directly affects the quality of human resource training.

Based on the analysis of the Industry 4.0 impact on the field of vocational education, the article has proposed solutions to develop technology applications in training and innovation of teaching methods, including: (1) Strengthening capacity in applying digital technology; (2) Building an online learning system and sharing digital teaching resources among schools; (3) Promoting innovation of teaching methods in the vocational education system. The synchronous implementation of these solutions will contribute to innovation and improving the quality of vocational education in the current context.

\section{References}

Ministry of Labour, Invalids and Social Affairs (2018), Draft of training and re-training pilot project for workers to adapt to the 4th industrial revolution, Hanoi, August 2018.

Lee Rainie (2017), 10 facts about jobs in the future, Pew Research Center's Internet \& American Life Project, https://www.slideshare.net.

Department of Teachers, General Department of Vocational Education (2018), Current situation and solutions to organizing vocational skills assessment to standardize the teaching staff, Document of Preliminary Conference on activities of assessing and certifying national vocational skills, Da Lat, October 2018.

Do Van Dung (2018), Solutions to develop educators of vocational education, Scientific discussion paper on the planning of the vocational education institution network and the development of vocational education institution 
teaching staff, National Council for Education and Human Resource Development, Education and Training Committee, Hai Phong, November 2018, p. 11-19.

Bui Van Hong and Le Van Ngoc (2018), Solutions to develop digital teaching under the Blended Learning model at the vocational training institution, Journal of Vocational Education Science, General Department of Vocational Education, Vol. 62 (November 2018), p. 45 - 45.

Bui Van Hong (2016), Developing the training program for technical teachers in orientation towards career skills at HCM University of Technology and Education, Journal of Science, Hanoi National University of Education, Vol. 61, No. 08 (2016), p. 107 - 116.

Bui Van Hong (2017), Integrating technology knowledge and practicing vocational skills in training technical teachers at HCM University of Technology and Education, Journal of Science, Hanoi National University of Education, Vol. 62, No. 04 (2017), p. 91 - 99.

Bui Van Hong (2018), IoT technology and digital classroom development application at HCM University of Technology and Education, Journal of Vocational Education Science, General Department of Vocational Education, Vol. 52 - 53 (January - February 2018), p. 90 - 98.

Duong Duc Lan (2018), Developing the vocational education institution network in an open, flexible way to meet the needs of vocational training and career for workers, Proceedings of Workshop on Development of the vocational education system in an open and flexible way to create opportunities for workers to train skills, start careers and work sustainably, September 2018, p. $77-80$.

National Assembly (2018), Resolution 63/2018/ QH14 on interrogation activities at the 5th meeting, XIV National Assembly, June 15, 2018.

Department of Teachers and Corporate Managers (2017), Orientation to build and develop teachers to meet the basic requirements of comprehensive reform of vocational education, General Department of Vocational Training, Ministry of Labour, Invalids and Social Affairs. 